\title{
Population Measures of Subjective Wellbeing: How Useful are they?
}

\author{
Richard Eckersley
}

Accepted: 5 October 2008/Published online: 19 October 2008

(C) Springer Science+Business Media B.V. 2008

\begin{abstract}
This article focuses on the contributions and, importantly, the limitations of subjective wellbeing (happiness/satisfaction) measures as indicators of broad population wellbeing and societal functioning. The popular practice of comparing happiness among countries gives a skewed view of how well their people are faring. Charting trends over time in happiness and mental health gives contradictory pictures of population wellbeing; even the responses to different questions within the same survey can yield very different findings. Asking people about their own lives and about social conditions produces contrasting results. These issues challenge the orthodox model of human development, which places Western liberal democracies at its leading edge. According to an alternative, psychosocial-dynamics, model, some, at least, may be societies in decline. Reconciling these views is no simple matter.
\end{abstract}

Keywords Social indicators - Subjective wellbeing - Happiness - National progress · Human development

\section{Introduction}

The growing scientific interest in subjective wellbeing (SWB) over the past decade or more has attracted attention, and found application, across a spectrum of scales and sectorsindividuals, organisations, communities and nations. Most public attention has focused on individual SWB; the "science of happiness" has added a whole new dimension to the burgeoning self-help and personal-growth industry.

This article develops themes presented in a closing address to the First Australian Positive Psychology and Wellbeing Conference, Sydney, 6 April, 2008.

R. Eckersley $(\bowtie)$

National Centre for Epidemiology and Population Health, The Australian National University,

Canberra, ACT 0200, Australia

e-mail: richard.eckersley@anu.edu.au 
This article is concerned with developments at the other end of the scale, which has been of greater political interest, and where SWB research has also added an important new perspective: the measurement of population wellbeing and national performance (e.g. Cummins et al. 2003; Diener and Seligman 2004; Diener 2006). Here, SWB (commonly measured as happiness or life satisfaction) has both coincided with, and contributed to, a growing questioning of the validity and adequacy of economic indicators, notably per capita income or GDP (Gross Domestic Product) as measures of national progress (Eckersley 2005, 2006).

While their very "subjectivity" has made national statistical agencies reluctant to adopt SWB measures (e.g. ABS 2006), they are an important addition to national indicators. Indeed, their correlation with the many, varied objective indicators of human development seemed to suggest "happiness" might be the holy grail of national indicators: a simple, easily understood and measured quality that could serve as a single measure of human wellbeing and social progress.

However, current SWB indicators also have their limitations. These have been noted in the SWB literature (e.g. Diener and Seligman 2004; Diener 2006). This article deals more comprehensively with these weaknesses (while also mentioning the benefits). It builds on earlier analyses that compared national measures of SWB and public perceptions of social quality of life (Eckersley 2000a, b, 2005, pp. 77-125). Specifically, the article will consider: international comparisons of SWB; time trends in SWB and mental health; comparisons of SWB and psychological wellbeing; people's perceptions of their own lives and the lives of others, or social conditions in general; and alternative national indicators to GDP, such as the Genuine Progress Indicator.

In essence, it argues that while SWB measures have helped to broaden the focus of social measurement beyond illbeing and the dominant economic indicators, and have provided a means of assessing the impact of various socio-economic and other factors on wellbeing, they present an overly positive view of modern western societies and the fundamental changes that are remaking them; they overestimate the positive effects and underestimate the negative.

\section{International Comparisons of SWB}

International comparisons of happiness and life satisfaction reveal large differences, with higher scores being associated with income, equality, individualism, human rights, social stability, democracy and even the (average) personality traits of people of different countries (Eckersley 2005, pp. 77-104). A recent global study (Inglehart et al. 2008) linked happiness to the extent to which a society allows free choice; free choice was, in turn, associated with economic development, democratization, and social liberalization.

Perhaps the most significant feature of these comparisons is the relationship to per capita income, or per capita GDP, given it is the standard measure of national performance, both relative to the past and to other countries. Generally speaking, increasing income confers large benefits at low income levels, but little, if any, benefit at high income levels (Diener and Diener 1995; Inglehart 2000; Eckersley 2005, pp. 32-35; Inglehart et al. 2008). Happiness levels off above about US\$10-15,000. (Life expectancy shows a similar relationship to income, plateauing at a per capita income of about US $\$ 5,000$.) Some economists continue to argue that a relationship between happiness and income exists at higher income levels, and demonstrate this by plotting the values on a log scale (e.g. 
Stevenson and Wolfers 2008). But the fact remains that rising income yields diminishing returns to happiness.

Nevertheless, when all the various factors are taken into account, it is the rich, liberal democracies of the West that do best in the SWB stakes. The benign perspective offered by the standard human development model is illustrated in this assessment by Inglehart et al. (2008):

By a favourable combination of circumstances, societal changes of the past two decades have increased both the prosperity of people in less-prosperous societies and the political and social freedom of people in middle-income and high-income societies, enhancing the extent to which people in both types of societies have free choice in how to live their lives. We hypothesize that these changes have been conducive to rising levels of happiness within entire societies.

However, just as income is an imperfect measure of population wellbeing, so too is SWB. For example, historians have noted that civilizations rise or fall on the confidence and optimism of their peoples (Eckersley 2005, pp. 122-125, 190). Given this, the results of the Pew Research Center's 2007 global attitudes survey are revealing (Pew 2007). Consider this comparison between the powerhouses of the West and East, the United States and China, the two countries widely seen as vying for dominance this century:

- Satisfaction with own life (7-10 on 0-10 scale): US 65\%, China $34 \%$.

- Satisfaction with state of nation: US $25 \%$, China $83 \%$.

- Satisfaction with national government: US 51\%, China $89 \%$.

- Next generation better off: US $31 \%$, China $86 \%$.

Broadly speaking, East and West differ on personal life satisfaction and next-generation optimism. (To take the example of a democratic Asian nation, the figures for India are, in order: $41 \%, 42 \%, 77 \%, 64 \%$.) The results may, in part at least, reflect response differences between individualistic and collectivist societies, and between stages of economic development. However, this does not necessarily negate their historic and geopolitical significance. (Satisfaction with the nation and with government fluctuates over the short term, so may not be good indicators of long-term confidence.)

Cross-cultural studies in wellbeing present a complex, even confusing, picture. Many looking at individualism and collectivism support the advantages to wellbeing of modern, secular, liberal democracies (Triandis and Suh 2002; Chirkov 2006; Triandis in press). Similarly, other studies exploring horizontal (egalitarian) and vertical (hierarchical) cultural orientations demonstrate the advantages of horizontal orientations in terms of meeting human needs and so enhancing wellbeing (Chirkov 2006). Many of the changes in modern Western culture would, on the face of it, seem to increase horizontal orientation, and so wellbeing.

However, there are also grounds for questioning this apparent supremacy. One is simply that individualists are more likely to deceive themselves about their own qualities, while collectivists' self-deceptions favour their group (as the above figures from the Pew survey suggest) (Triandis in press). Also, there may be complex tradeoffs between the individual and groups and between the present and the future in optimizing population wellbeing. For example, research shows that some differences in SWB between nations appear to be due to the fact that people value SWB differently. As Diener et al. (2003) note, "people may trade some amount of positive emotions in order to obtain other things they value". They cite research showing that, in contrast to Asian-American students, Caucasian-American students were happiest engaged in activities important to them at that moment rather than 
those related to important future goals. Caucasian Americans were also more likely to switch tasks when they were not performing a task well, enhancing their happiness in the process, rather than persevere in order to master it.

Other cross-cultural studies suggest collectivists have a higher tolerance for contradictions, cope better with change, are more flexible across social situations, and think more holistically (Triandis and Suh 2002; Koltko-Rivera 2004). Thus Koltko-Rivera (2004) says an extensive body of research shows that East Asians exhibit "holistic" cognition, characterized by paying attention to the entire stimulus field and the use of dialectical reasoning, while Americans exhibit "analytical" cognition, characterized by paying attention to isolated details and the use of Aristotelian-type logic. These differences have obvious implications for how societies deal with modern conditions and challenges. Even the most cursory assessment of China and the United States today exposes the danger of using the above happiness scores as a measure of their national performance.

The potential tension between seeking personal happiness and social functioning is also illustrated by the psychosocial dynamics of global threats such as climate change, as well as more general concerns about the state of society and the world (Eckersley 2007a, 2008a). Evidence suggests people are responding in at least three different ways to "apocalyptic suspicions" about the 21st century: nihilism (the abandonment of belief in a social or moral order; decadence rules), fundamentalism (the retreat to certain belief; dogma rules), and activism (the transformation of belief; hope rules). Each of these responses offers benefits to SWB, but in quite different ways: nihilism through disengagement and distraction from frightening possibilities and prospects; fundamentalism through the conviction of righteousness and the promise of salvation; and activism through a unity of purpose and a belief in a cause. Yet only one-activism-will allow us to deal constructively with global threats.

\section{National Patterns and Trends in Happiness}

When we turn to differences in SWB within populations, rather than between them, SWB measures usefully reveal, and quantify, the effects of different demographic and other characteristics. An Australian wellbeing index shows that people with the highest SWB tend to be older, well-off, and living with their partners; those with the lowest SWB are more likely to be poor, unemployed, living alone, divorced or separated, and single parents (Australian Unity \& Deakin University 2008). The happiest groups have an index score of over $80 \%$, the unhappiest less than $60 \%$.

Thus the rich are happier than the poor, especially in poorer countries but even in rich nations (Diener and Seligman 2004; Eckersley 2005, pp. 77-82; Australian Unity \& Deakin University 2008). While it is often said that money cannot buy happiness, most surveys reveal the two are linked (although the relationship is likely to be reciprocal). They also show, however, that the relationship is strongest at low incomes, where money improves living conditions and alleviates hardship. Above this level, wealth has symbolic value as a measure of social status, and status affects wellbeing through the social comparisons it defines. So income-related differences in happiness will persist no matter how high average incomes rise through economic growth.

Despite the link between money and happiness, surveys show average population SWB has not increased in recent decades in rich nations (over 50 years in the United States). Given the dramatic social changes over this period, including growing affluence, this in itself casts doubts on the effectiveness of SWB indicators. However, reflecting the 
non-linear relationship between average national income and SWB, as well as increasing democratization and social liberalization, there is evidence that SWB has increased over time, especially in developing countries (Inglehart et al. 2008). The Pew's global attitudes survey (Pew 2007) also found personal life satisfaction remained quite stable for developed countries between 2002 and 2007 (US 65-65\%, Western Europe median 53-53\%), but it rose in many developing countries (China 23-34\%, India 29-41\%).

\section{National Patterns and Trends in Health}

Turning to health, the orthodox view is of continuing improvement, in line with historic trends (Eckersley 2007b, 2008b, in press). This view is based mainly on declining mortality and so rising life expectancy as a measure of overall population health, as well as high levels of self-reported health and life satisfaction. (Globally, life expectancy has more than doubled in the last 100 years, and is still rising; it is undoubtedly one of humanity's greatest achievements.) Thus it might be argued that if income and health are increasing, and SWB is stable, this still represents solid social progress. However, while mortality might once have been a good summary measure of health, this is now questionable. The orthodox view underestimates the growing importance to overall health and wellbeing of non-fatal, chronic illness, especially mental illness (Eckersley 2007b, 2008b, in press).

This "mismeasure" is especially relevant to young people's health, an important predictor of future population health. To take Australia as an example of the rich world, death now strikes very few young people: about 40 in every 100,000 each year (AIHW 2007). Also the major causes of death do not necessarily reflect underlying changes in physical and mental health (especially the biggest killer, road accidents). On the other hand, research in Australia and other developed nations suggests $20-30 \%$ of young people (2030,000 per 100,000) are suffering significant psychological distress at any one time, with less severe stress-related symptoms such as frequent headaches, stomach-aches and insomnia affecting as many as 50\% (Eckersley 2007b, 2008b, in press).

Australians aged 18-24 are experiencing mental health problems at over four times the rate of those aged 60 and over (ABS 1998). Mental disorders account for almost half the total "burden of disease" in Australians aged 15-24, measured as both death and disability-far more than the second biggest contributor, injuries (AIHW 2007). For the Australian population as a whole, mental disorders are the third largest contributor to the total burden of disease, after cancer and cardiovascular disease, and the largest contributor to the non-fatal component of the disease burden (AIHW 2008).

While such findings imply a worsening situation, long-term trends in mental health are very difficult to establish conclusively because of the lack of good, comparative data. The issue remains contentious; not all studies show an increase. However, the weight of international evidence indicates the prevalence of psychological problems among young people has risen in developed nations in recent decades (Eckersley 2007b, 2008b, in press). The trends are despite the increased treatment of mental disorders.

\section{Health, Happiness and Optimism}

The findings on happiness and health, sometimes emerging from the same surveys, illustrate the contrasting pictures that emerge from different measures-and the danger in 
taking both self-reported health and happiness measures at face value, as the orthodox view does.

A survey (Bernard et al. 2007) of more than 10,000 Australian students from prep school (age 4-6) to year 12 (age 17-18) found that while $89 \%$ of the students said they were happy, about $40 \%$ scored in the lower levels of social and emotional wellbeing. Between a fifth and a half of students said they: were lonely (18\%); had recently felt hopeless and depressed for a week and had stopped regular activities (20\%); were very stressed (31\%); had difficulty controlling how depressed they got (32\%); lost their temper a lot $(35 \%)$; worried too much (42\%); and had difficulty calming down when upset (48\%).

Several surveys by the Australian Childhood Foundation (Tucci et al. 2005, 2006, 2007) of children 10-14 or 10-17 produce a similar picture of high levels of stress, worry and anxiety. For substantial minorities, increasing to majorities for some questions, their sense of confidence in themselves, their community and their place in the world is under threat. Based on one survey (Tucci et al. 2007), the foundation established three categories of children: those who felt well-connected and supported-52\%; a "worried" group $-42 \%$; and a "disconnected and insular" group (the most vulnerable) $-8 \%$.

Similarly, another study (Smart and Sanson 2005) found that over $80 \%$ of young people were satisfied with their lives-including lifestyle, work or study, relationships with parents and friends, accomplishments and self-perceptions. However, 50\% were experiencing one or more health problems associated with depression, anxiety, anti-social behaviour and alcohol use. In other words, most of those with problems were satisfied with life.

The explanations for the apparent contradictions are complex, and include that evaluating one's happiness involves habituation, self-illusions, rationalization and mitigation, and that some "unhealthy" behaviours (such as illicit drug use or binge drinking) can be considered part of enjoying life and coping with stress. The different pictures also reveal the difference between the public mask and the private person, especially, in the case of young people, the vulnerability, anxiety and insecurity that are often hidden behind an outward show of self-confidence, worldiness and "cool". Even seriously depressed people can lead outwardly normal, even successful, lives.

The same issue arises with self-reported health (which strongly correlates with happiness and life satisfaction). Over 90\% of Australians aged 15-24 assessed themselves to be in excellent, very good or good health (AIHW 2007). Yet among Australians who reported mood disorders as a long-term health condition, $30 \%$ rated their health as excellent or very good, $31 \%$ rated it as good, and only $39 \%$ rated it as fair or poor; the proportions were the same for those who reported five or more long-term health conditions (AIHW 2006). While selfreported health is correlated to actual health, it is not an accurate measure of health status.

When we turn to optimism, we get a different sort of contrast. Personal optimism is associated with SWB, and over $80 \%$ of young Australians say they are personally optimistic about their own lives. This proportion has not changed over the past 20 years (like happiness, it tends to be a stable measure at the population level) (Eckersley et al. 2007). However, a growing proportion of young people appears to be socially pessimistic (an outlook shared by older people). Almost half believe quality of life in Australia is declining (despite a long economic boom that has seen strong economic growth, declining unemployment and rising incomes); the gap between their expected and preferred futures for Australia has widened; and concerns about the future of the world have increased (Eckersley et al. 2007). In one survey (Tucci et al. 2006), almost two-thirds of children aged 10-17 either did not believe (18\%), or were unsure (44\%), that their generation would be better off than their parents; $27 \%$ were concerned the world would end before they got old. Such findings are part of a wider picture of people's disquiet about social trends. 


\section{Perceptions of Quality of Life}

Many studies over the past decade, both qualitative and quantitative, reveal levels of anger and anxiety about changes in society that were not apparent 30 years ago (Eckersley 2005, pp. 105-125). The studies show many people are concerned about the materialism, greed and selfishness they believe drive society today, underlie social ills, and threaten their children's future. They yearn for a better balance in their lives, believing that when it comes to things like individual freedom and material abundance, people don't seem "to know where to stop" or now have "too much of a good thing".

While I am drawing mainly on Australian, American, and British studies, the generic and fundamental nature of people's concerns about society suggest the findings would, to varying degrees, be true of other Western nations. People in developing countries may still share a faith in material progress and have most to gain from what it offers. Nevertheless, the issues I discuss are still relevant to their world and the choices they make.

A report on "the mind and mood" of Australians (Ipsos Mackay 2005) says there is growing concern about the state of Australian society-rougher, tougher, more competitive, less compassionate-that is producing stress, edginess and a feeling of personal vulnerability. Australians feel they "seem to lurching from one difficulty to another with the prospect of a serious crisis emerging". The blame is repeatedly directed at political leaders, who are accused of "short-term thinking" and neglecting to invest in the country's future. One survey (Tucci et al. 2005) reported "a growing sense among parents that childhood is at risk because the daily environment in which children live is perceived to be increasingly less safe, stable and predictable". It found that $80 \%$ or more of parents believed children were growing up too fast; worried about their children's futures; and felt children were targeted too much by marketers.

A US survey (Center for a New American Dream 2004) echoes the findings of a similar, earlier survey (Harwood Group 1995) in underscoring Americans' concerns about their way of life. Large majorities believe that the country is not focused on the right priorities, with too much emphasis on work and money and not enough on family and community; and that American society is too materialistic, with serious consequences for children, society, the environment and the world. A British study found that despite higher incomes, better health and greater opportunity for women, Britons were increasingly depressed, unhappy in their relationships, and alienated from civic society (Woodward 2003).

The concerns people express about life today and in the future are important to social cohesion and functioning because they weaken people's belief in a broader social ideal and a commitment to the common good, so reinforcing individual goals and priorities. They can also impact on personal wellbeing. Psychological research shows that viewing the world as comprehensible, manageable and meaningful is associated with wellbeing (Eckersley 2005, pp. 77-104). Biomedical research shows that people become more stressed and more vulnerable to stress-related illness if they interpret the stress as evidence that circumstances are worsening, feel they have little control over its causes, and don't know how long it will last (Sapolsky 2005).

\section{Alternative Measures of Progress}

Consistent with the evidence I have discussed above about the growing gap between economic performance and quality of life, researchers have proposed a threshold hypothesis, which states that for every society there seems to be a period in which 
economic growth (as conventionally measured) brings about an improvement in quality of life, but only up to a point - the threshold point-beyond which, if there is more economic growth, quality of life may begin to deteriorate (Max-Neef 1995; Eckersley 2005, pp. 32-35).

The threshold hypothesis has been supported in the past decade by the development of indices, such as the Genuine Progress Indicator, that adjust GDP for a range of social, economic and environmental factors that GDP either ignores or measures inappropriately. These include income distribution, unpaid housework and voluntary work, loss of natural resources, and the costs of unemployment, crime and pollution. These "GDP analogues" show that trends in GDP and social wellbeing, once moving together, have diverged since about the mid-1970s in most, if not all, countries for which they have been constructed, including the United States, Britain and Australia (Max-Neef 1995; Hamilton and Denniss 2000; Nef 2004; Talberth et al. 2007).

\section{Explanations}

Further evidence against the "richer, healthier and happy" view of modern life comes from the research into the social determinants of health. The following factors relate primarily to the social and emotional wellbeing of young people, but they also have a broader relevance to the social dis-ease discussed above. They include (Eckersley 2007b, 2008b, in press):

- Changes in the worlds of family, work and education such as family conflict and breakdown, poverty and unemployment, job stresses and insecurity, and education pressures (the most commonly cited factors).

- Cultural changes-for example, excessive materialism and individualism, which reduces both social support and personal control.

- Increased media use and changing media content, linked to violence, consumerism, loss of community and social cohesion, vicarious life experiences, invidious social comparisons, and pessimism about global conditions and futures.

- The decline of religion, which "packages" many sources of wellbeing, including social support, spiritual or existential meaning, a coherent belief system and a clear moral code (paradoxically, however, at a population or national level, research suggests religion is a health burden).

- Changes in diet, which have been implicated in many chronic health problems. For example, a large increase in the ratio of omega 6 to omega 3 fatty acids has been linked to cardiovascular disease and mood disorders.

- Comorbidity, especially between drug use and mental illness, but also between mental and physical problems such as the links between obesity and depression, and depression and heart disease.

- Environmental degradation, including widespread toxic chemical pollution, which affects neurological development and immune function.

Any assessment of population wellbeing and societal functioning has to include a futures perspective. Environmental changes loom large as a future risk to health and wellbeing, especially global warming and its consequences. A major WHO report (Corvalan et al. 2005) warns that the dual trends of the growing exploitation of ecosystems and their generally declining condition are unsustainable. There is an increasing risk of "non-linear changes" in ecosystems, including accelerating, abrupt and potentially irreversible changes, which could have "a catastrophic effect on human health". The United Nations 
Human Development Report (HDR 2008, p. 7) warns of climate change: "Today, we are witnessing at first hand what could be the onset of major human development reversal in our lifetime".

Of course, there have also been social improvements, including greater gender, religious, ethnic and racial equality and tolerance; and environmental improvements, such as cleaner urban air and water in the developed world (including reduced lead pollution). I am focusing in this section on possible explanations for the adverse trends in health, especially mental health.

There are several important points to note about these explanatory factors:

- They interact with other biological and social factors to produce individual, age and generational differences.

- The health effects are not usually independent, direct and immediate; rather the causal pathways are complex, effects being often interdependent, indirect, delayed, and spanning different levels or layers of causation.

- Trends in many of these factors provide indirect corroboration of the evidence that mental health problems have risen.

\section{Conclusion}

The "science of happiness" has added important elements to our understanding, not just of individual SWB, but also of population wellbeing and societal functioning. It has helped to shift the focus of attention from illbeing to wellbeing, and to its causes and correlates, and from the dominant economic perspective on progress. SWB is also a useful relative measure to compare the effects on SWB of demographic characteristics and psychological qualities.

However, SWB is a dubious measure for comparing countries because of cultural differences in response and because other attributes and attitudes also need to be considered in assessing national performances. SWB is not a valid absolute measure of wellbeing because the picture it presents is partial, at best, and differs markedly from that painted by other measures, notably those of mental health, social perceptions, and "genuine progress".

Most strikingly, when we plot the happiness of countries against wealth, freedom or other correlates, the Western liberal democracies invariably dominate the top right-hand corner; they seem to be on the right track of human development. Yet when we look "inside" these societies at their psychosocial dynamics and how these have played out over time, a very different picture emerges; some, at least, could be societies in decline.

The contrast between the two views could scarcely be more marked (see, especially, Inglehart et al. (2008) for a contrary perspective to that presented here). Reconciling them presents science with a formidable challenge. To begin the process, it is noteworthy that the orthodox human development model emphasizes the association between a single and, I have argued, inadequate measure of wellbeing (SWB or life expectancy) and mainly material and structural developments (for example, standard of living, education, democratic government, and human rights) and, in the case of Inglehart et al. (2008), specific instances of social liberalization (for example, religious, ethnic and sexual tolerance). The psychosocial-dynamics model of human development emphasizes associations between multiple measures of wellbeing and broader, cultural and moral causes and correlates (for example, the effects of materialism and individualism on identity, belonging and meaning in life). 
The standard human development model may be useful in evaluating earlier stages of human development, but it is less relevant in assessing so-called highly developed societies. Across all stages, but especially in the latter cases, it needs to be supplemented by the psychosocial-dynamics model of human development. To cite a specific issue, the freedom of choice that appears central to SWB under the standard model (Inglehart et al. 2008) may, in fact, not be measuring what is intended, and so not be the positive quality it seems, a point discussed at length in the context of an analysis of youth suicide in developed nations (Eckersley and Dear 2002; Eckersley 2005, pp. 170-184). Among several possibilities, free choice may serve individuals well, but at the societal level it may reduce social cohesion and support, leading to more personal isolation and alienation, and so to higher suicide rates (but, again, see Inglehart et al. (2008), for a different interpretation).

If there is a "holy grail" of a single indicator that accurately measures how well nations and people are faring, SWB is not it; the search must continue. In the meantime, we will have to use a wide variety of measures-objective and subjective, social, cultural, economic, and environmental - to guide our choices and decisions in seeking to make the most of being human and human wellbeing.

\section{References}

ABS. (1998). Mental health and wellbeing: Profile of adults, Australia 1997. Cat. No. 4326.0. Canberra: Australian Bureau of Statistics.

ABS. (2006). Measures of Australia's progress 2006. Cat. No. 1370.0. Canberra: Australian Bureau of Statistics.

AIHW. (2006). Australia's health 2006. AIHW Cat. No. AUS 73. Canberra: Australian Institute of Health and Welfare.

AIHW. (2007). Young Australians: Their health and wellbeing 2007. Cat No. PHE 87. Canberra: Australian Institute of Health and Welfare.

AIHW. (2008). Australia's health 2008. AIHW Cat. No. AUS 99. Canberra: Australian Institute of Health and Welfare.

Australian Unity \& Deakin University. (2008). What makes us happy? Melbourne: Australian Unity, Deakin University. Retrieved 17 Sept 2008 from www.deakin.edu.au/research/acqol/index_ wellbeing/Survey_18.2.pdf.

Bernard, M. E., Stephanou, A., \& Urbach, D. (2007). The ASG student social and emotional health report. Oakleigh, Vic: Australian Scholarships Group. Retrieved 7 Sept 2008 from www.asg.com.au/ socialemotional.

Center for a New American Dream. (2004). More of what matters. New American dream survey report, September 2004. Maryland: Center for a New American Dream. Retrieved 7 Sept 2008 from http://www.newdream.org/about/pdfs/Finalpollreport.pdf.

Chirkov, V. I. (2006). Multiculturalism and human nature: A psychological view. In D. Zinga (Ed.), Navigating multiculturalism: Negotiating change (pp. 33-57). Newcastle upon Tyne: Cambridge Scholars Publishing.

Corvalan, C., Hales, S., McMichael, A., et al. (2005). Ecosystems and human wellbeing: Health synthesis. A report of millennium ecosystem assessment. Geneva: World Health Organization.

Cummins, R. A., Eckersley, R., Pallant, J., Van Vugt, J., \& Misajon, R. (2003). Developing a national index of subjective wellbeing: The Australian Unity Wellbeing Index. Social Indicators Research, 64, 159190. doi:10.1023/A:1024704320683.

Diener, E. (2006). Guidelines for national indicators of subjective wellbeing and illbeing. Journal of Happiness Studies, 7(4), 397-404. doi:10.1007/s10902-006-9000-y.

Diener, E., \& Diener, C. (1995). The wealth of nations revisited: Income and quality of life. Social Indicators Research, 36, 275-286. doi:10.1007/BF01078817.

Diener, E., Oishi, S., \& Lucas, R. E. (2003). Personality, culture, and subjective wellbeing: Emotional and cognitive evaluations of life. Annual Review of Psychology, 54, 403-425. doi:10.1146/annurev.psych. 54.101601.145056. 
Diener, E., \& Seligman, M. E. P. (2004). Beyond money: Toward an economy of wellbeing. Psychological Science in the Public Interest, 5(1), 1-31. doi:10.1111/j.0963-7214.2004.00501001.x.

Eckersley, R. (in press). Progress, culture and young people's wellbeing. In A. Furlong (Ed.), International handbook of youth and young adulthood. London: Routledge.

Eckersley, R. (in press). The health and well-being of young Australians: Patterns, trends, explanations and responses. In D. L. Bennett, S. J. Towns, E. L. Elliott \& J. Merrick (Eds.), Challenges in adolescent health: An Australian perspective. Victoria, BC: International Academic Press.

Eckersley, R. (2000a). The mixed blessings of material progress: Diminishing returns in the pursuit of happiness. Journal of Happiness Studies, 1(3), 267-292. doi:10.1023/A:1010040010239.

Eckersley, R. (2000b). The state and fate of nations: Implications of subjective measures of personal and social quality of life. Social Indicators Research, 52, 3-27. doi:10.1023/A:1007071621613.

Eckersley, R. (2005). Well and good: Morality, meaning and happiness (2nd ed.). Melbourne: Text Publishing.

Eckersley, R. (2006). Progress, sustainability and human wellbeing: Is a new worldview emerging? International Journal of Innovation and Sustainable Development, 1(4), 304-317. doi:10.1504/IJISD.2006. 013733.

Eckersley, R. (2007a). What's wrong with the official future? In G. Hassan (Ed.), After Blair: Politics after the New Labour decade (pp. 172-184). London: Lawrence and Wishart.

Eckersley, R. (2007b). The health and wellbeing of young Australians: Present patterns and future challenges. International Journal of Adolescent Medicine and Health, 19(3), 217-227.

Eckersley, R. (2008a). Nihilism, fundamentalism, or activism: Three responses to fears of the Apocalypse. The Futurist, 42(1), 35-39.

Eckersley, R. (2008b). Never better-or getting worse? The health and wellbeing of young Australians. Canberra: Australia 21 Ltd. Retrieved 17 Sept 2008 from http://www.australia21.org.au/pdf/Youth \%20Health\%20Text\%2008.pdf.

Eckersley, R., Cahill, H., Wierenga, A., \& Wyn, J. (2007). Generations in dialogue about the future: The hopes and fears of young Australians. Canberra: Australia 21 Ltd; Melbourne: Australian Youth Research Centre. Retrieved 17 Sept 2008 from http://www.australia21.org.au/pdf/youth_futures.pdf.

Eckersley, R., \& Dear, K. (2002). Cultural correlates of youth suicide. Social Science and Medicine, 55, 1891-1904. doi:10.1016/S0277-9536(01)00319-7.

Hamilton, C., \& Denniss, R. (2000). Tracking wellbeing in Australia: The Genuine Progress Indicator 2000, Discussion paper no. 35. Canberra: the Australia Institute. Retrieved 30 Sept 2008 from www.tai. org.au/?q=node/8.

Harwood Group. (1995). Yearning for balance. Report for Merck Family Fund. Retrieved 17 Sept 2008 from www.iisd.ca/consume/harwood.html.

HDR. (2008). Fighting climate change: Human solidarity in a divided world. Human Development Report 2007/2008. UN Development Program. Retrieved 30 Sept 2008 from http://hdr.undp.org/en/.

Inglehart, R. (2000). Globalisation and postmodern values. The Washington Quarterly, 23(1), 215-228. doi: 10.1162/016366000560665.

Inglehart, R., Foa, R., Peterson, C., \& Welzel, C. (2008). Development, freedom, and rising happiness: A global perspective (1981-2007). Perspectives on Psychological Science, 3(4), 264-285. doi: 10.1111/j.1745-6924.2008.00078.x.

Ipsos Mackay. (2005). Mind and mood, The Ipsos Mackay Report no. 116. Sydney: Ipsos Mackay Public Affairs.

Koltko-Rivera, M. E. (2004). The psychology of worldviews. Review of General Psychology, 8(1), 3-58. doi:10.1037/1089-2680.8.1.3.

Max-Neef, M. (1995). Economic growth and quality of life: A threshold hypothesis. Ecological Economics, 15, 115-118. doi:10.1016/0921-8009(95)00064-X.

Nef. (2004). Chasing progress: Beyond measuring economic growth. London: New Economics Foundation.

Pew. (2007). Global opinion trends 2002-2007. Pew Global Attitudes Project. Washington: Pew Research Center. Retrieved 30 Sept 2008 from http://pewglobal.org/reports/display.php?ReportID=257.

Sapolsky, R. (2005, December). Sick of poverty. Scientific American Website.

Smart, D., \& Sanson, A. (2005). What is life like for young Australians today, and how well are they faring? Family Matters (Melbourne, Vic.), 70, 46-53.

Stevenson, B., \& Wolfers, J. (2008). Economic growth and subjective wellbeing: Reassessing the Easterlin paradox (unpublished manuscript). Retrieved 17 Sept 2008 from http://bpp.wharton.upenn.edu/betseys/ papers/Happiness.pdf.

Talberth, J., Cobb, C., \& Slattery, N. (2007). The genuine progress indictor 2006: A tool for sustainable development. Oakland, CA: Redefining Progress. Retrieved 17 Sept 2008 from www.rprogress.org/ sustainability_indicators/genuine_progress_indicator.htm. 
Triandis, H. C. (in press). Fooling ourselves: Self-deception in politics, religion, and terrorism. Westport, CT: Praeger, Greenwood Publishing Group.

Triandis, H. C., \& Suh, E. M. (2002). Cultural influences on personality. Annual Review of Psychology, 53, 133-160. doi:10.1146/annurev.psych.53.100901.135200.

Tucci, J., Mitchell, J., \& Goddard, C. (2005). The changing face of parenting. Melbourne: Australian Childhood Foundation, April. Retrieved 30 Sept 2008 from http://www.childhood.org.au/research/ reports.asp.

Tucci, J., Mitchell, J., \& Goddard, C. (2006). Every child needs a hero. Melbourne: Australian Childhood Foundation, July. Retrieved 30 Sept 2008 from http://www.childhood.org.au/research/reports.asp.

Tucci, J., Mitchell, J., \& Goddard, C. (2007). Children's fears, hopes and heroes. Melbourne: Australian Childhood Foundation, June. Retrieved 30 Sept 2008 from http://www.childhood.org.au/research/ reports.asp.

Woodward, W. (2003). An affluent but more anxious society. Guardian Weekly, 27 February-5 March, 11. 